\title{
White Cord Syndrome Causing Transient Tetraplegia After Posterior Decompression and Fusion
}

\author{
Christopher D. Busack, MD, Bernard E. Eagleton, MD \\ Department of Anesthesiology, Tulane University School of Medicine, New Orleans, LA
}

Background: New neurologic deficits after spine surgery occur in less than $1 \%$ of cases. A particularly rare complication is white cord syndrome, a neurologic deterioration in the absence of obvious perioperative injury with concurrent hyperintense signal change on T2-weighted magnetic resonance imaging. The pathophysiologic mechanism is hypothesized to be an ischemiareperfusion injury after the decompression of a chronically ischemic cord.

Case Report: A 63-year-old male underwent posterior cervical decompression and fusion for severe cervical stenosis and myelopathy. During the procedure, intraoperative neurophysiologic monitoring signals were lost. The patient developed acute postoperative tetraplegia attributed to white cord syndrome. Motor and sensory deficits improved after intravenous dexamethasone and intensive physical therapy.

Conclusion: The pathophysiology of white cord syndrome is unclear, and intraoperative anesthetic management strategies to prevent this syndrome are unknown. This case serves to educate perioperative physicians to suspect this rare syndrome, encourage research into its pathophysiology, and guide clinicians in formulating therapeutic regimens.

Keywords: Anesthesia, ischemia, neurophysiological monitoring, neurosurgery, perfusion, quadriplegia

Address correspondence to Bernard E. Eagleton, MD, Department of Anesthesiology, Tulane University School of Medicine, 1430 Tulane Ave., HC73, New Orleans, LA 70112-2532. Tel: (504) 988-5903. Email: beagleton@tulane.edu

\section{INTRODUCTION}

New neurologic deficits are rare complications following spine surgery, occurring at a rate less than $1 \% .^{1,2}$ The rate may be higher in specific patients with severe spinal stenosis, as one review of 114 patients demonstrated a complication rate of nearly $8 \% .^{3}$ A retrospective review of 11,817 patients with new deficits revealed epidural hematoma, inadequate decompression, and acute ischemia to be the most common causes of neurologic complications, with incidences of $38 \%, 23 \%$, and $19 \%$, respectively. ${ }^{1}$ The routine use of intraoperative neurophysiologic monitoring (IONM) detects neurologic deficits with $>90 \%$ sensitivity, allowing perioperative physicians to alter management to resolve the insult.

Recent case reports (published from 2013 to 2018) describe a novel pathophysiologic phenomenon called white cord syndrome (Table), ${ }^{4-7}$ neurologic deterioration with concurrent hyperintense signal change on T2-weighted magnetic resonance imaging (MRI) in the absence of obvious perioperative complications. T2 hyperintensity is a nonspecific finding but indicates an increase in water content in the area, as seen with acute ischemia or demyelination. ${ }^{8}$ The pathophysiologic mechanism of white cord syndrome is hypothesized to be ischemia-reperfusion injury via damaging oxygen-derived free radicals following the acute reperfusion of chronically ischemic tissue. .,6 $^{4,}$
To our knowledge, this report is the fifth published case of a patient who developed white cord syndrome.

\section{CASE REPORT}

A 63-year-old male with a 1-year history of progressive difficulty walking, declining balance, and neuropathic pain in his extremities (Nurick grade 3, modified Japanese Orthopaedic Association [mJOA] score of 15) presented to the preoperative testing clinic in preparation for a C3C6 laminectomy and C2-T1 posterior fusion. Cervical MRI demonstrated severe cervical stenosis from C2-C3 to C5-C6 with associated hyperintense intramedullary signal change at C5-C6 (Figure 1).

The patient's medical history was notable for a 15 packyear smoking history and poorly controlled hypertension. He took metoprolol tartrate $25 \mathrm{mg}$ twice daily and oxycodone 20 mg twice daily. His surgical history included a remote lumbar transforaminal interbody fusion in 2001. The patient's temperature was $36^{\circ} \mathrm{C}$, blood pressure was $189 / 96 \mathrm{mmHg}$, and heart rate was $54 \mathrm{bpm}$. Physical examination was notable for decreased cervical range of motion because of pain. The patient exhibited 5/5 strength in all muscle groups of the upper and lower extremities except for 4/5 strength in bilateral biceps and triceps. Sensation to light touch was decreased in bilateral upper and lower extremities. Bilateral upper and lower extremities revealed hyperreflexia. The 
Table. Published Reports of White Cord Syndrome

\begin{tabular}{|c|c|c|c|c|}
\hline Case Report & Preoperative Deficit & Surgical Case & Postoperative Deficit & Intervention \\
\hline $\begin{array}{l}\text { Chin et al, } \\
2013^{4}\end{array}$ & $\begin{array}{l}\text { Radiculomyelopathic } \\
\text { pain, ataxia, Nurick } \\
\text { score } 3\end{array}$ & $\begin{array}{l}\text { C4-C5, C5-C6 anterior } \\
\text { cervical discectomy } \\
\text { and fusion }\end{array}$ & $\begin{array}{l}\text { C6 incomplete tetraplegia, } \\
\text { new left-sided weakness }\end{array}$ & $\begin{array}{l}\text { Hydrocortisone, inpatient } \\
\text { rehabilitation, Nurick } \\
\text { score } 4\end{array}$ \\
\hline $\begin{array}{l}\text { Giammalva } \\
\text { et al, } 2017^{5}\end{array}$ & $\begin{array}{l}\text { Radiculomyelopathic } \\
\text { pain, gait disturbance, } \\
\text { urinary incontinence, } \\
\text { spastic tetraparesis, } \\
\text { Nurick score } 3\end{array}$ & $\begin{array}{l}\text { C3-C4, C5-C6 anterior } \\
\text { cervical discectomy } \\
\text { and fusion }\end{array}$ & $\begin{array}{l}\text { Tetraparesis with complete } \\
\text { paraplegia, motor } \\
\text { weakness to upper limbs } \\
\text { with diffuse spastic } \\
\text { hypertonia }\end{array}$ & $\begin{array}{l}\text { Methylprednisolone, } \\
\text { inpatient rehabilitation, } \\
\text { Nurick score } 4\end{array}$ \\
\hline $\begin{array}{l}\text { Antwi et al, } \\
2018^{6}\end{array}$ & $\begin{array}{l}\text { Intermittent paresthesias, } \\
\text { numbness, balance } \\
\text { difficulties, Nurick } \\
\text { score } 1\end{array}$ & $\begin{array}{l}\text { C4-C7 posterior } \\
\text { decompression via } \\
\text { laminectomy, C3-C7 } \\
\text { instrumented } \\
\text { arthrodesis }\end{array}$ & Left-sided hemiparesis & $\begin{array}{l}\text { Methylprednisolone, } \\
\text { dexamethasone taper, } \\
\text { inpatient rehabilitation, } \\
\text { Nurick score } 4\end{array}$ \\
\hline $\begin{array}{l}\text { Vinodh et al, } \\
2018^{7}\end{array}$ & $\begin{array}{l}\text { Paraparesis, acute urinary } \\
\text { retention }\end{array}$ & $\begin{array}{l}\text { C2-C5 posterior } \\
\text { laminectomy } \\
\text { C1-C2, C5-C6 fusion }\end{array}$ & C3 quadriplegia & $\begin{array}{l}\text { Dexamethasone, palliative } \\
\text { care }\end{array}$ \\
\hline
\end{tabular}

patient's laboratory values were notable for hemoglobin of $15 \mathrm{~g} / \mathrm{dL}$.

On the morning of surgery, the patient's blood pressure was $159 / 90 \mathrm{mmHg}$ (mean arterial pressure [MAP] of $113 \mathrm{mmHg}$ ), and his heart rate was $64 \mathrm{bpm}$. In the operating room, the patient was positioned in neutral cervical position, and lack of symptoms was confirmed in this

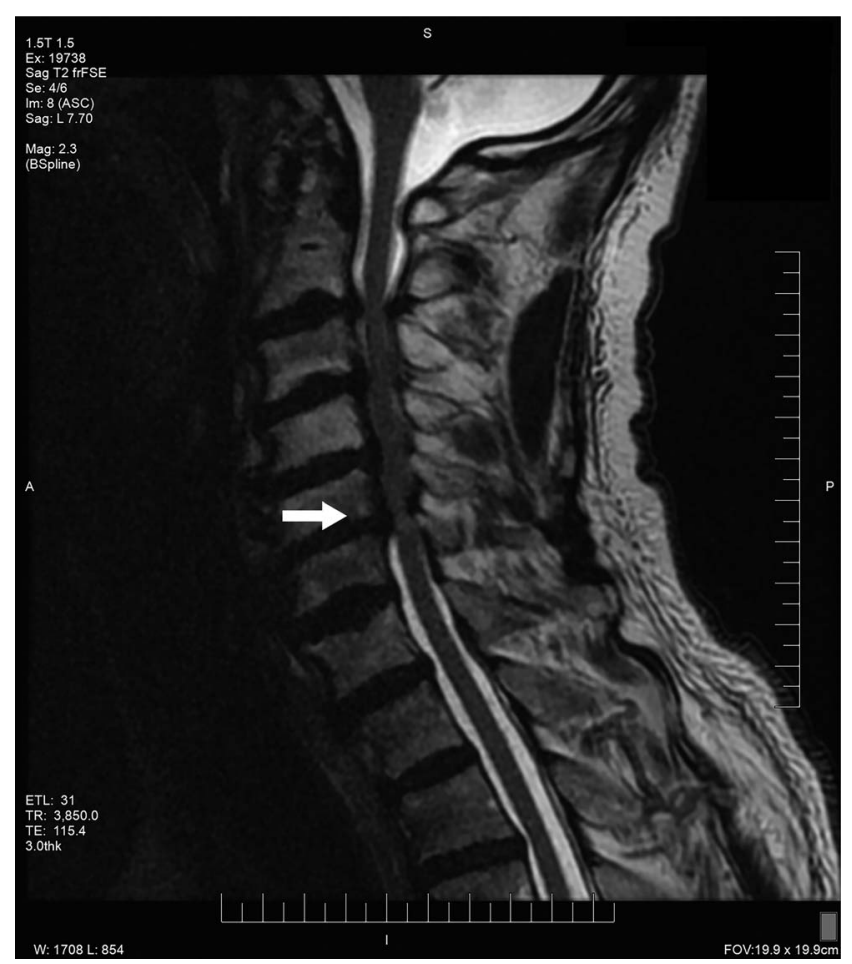

Figure 1. Preoperative T2-weighted magnetic resonance sagittal image of 63-year-old-male with severe cervical spinal stenosis demonstrates myelopathy with associated hyperintensity at the C5-C6 level (arrow). position prior to administration of induction medications. General anesthesia was induced with propofol, fentanyl, lidocaine, ketamine, and succinylcholine. Gentle bag mask ventilation was achieved during maintenance of manual inline stabilization. Video-assisted laryngoscopy (Storz CMAC) obtained a Cormack-Lehane grade 1 view, and endotracheal intubation was secured. General anesthesia was maintained with dexmedetomidine $(0.1 \mathrm{mcg} / \mathrm{kg} / \mathrm{h})$, propofol (100 $\mathrm{mcg} / \mathrm{kg} / \mathrm{min})$, and inhaled sevoflurane (1\%). The patient underwent C3-C6 posterior decompression via laminectomy and C2-T1 instrumented fusion. The spinal cord and exiting nerve roots were decompressed via total foraminotomies. Bispectral index, somatosensory evoked potentials (SSEPs), and motor evoked potentials (MEPs) were monitored throughout the procedure. The MAP goal of $>85 \mathrm{mmHg}$ was achieved with ephedrine and phenylephrine. Systolic blood pressure $>200 \mathrm{mmHg}$ was treated with fentanyl and nicardipine.

Ninety minutes after incision, when the laminectomies were completed, the neurophysiologist noted the abrupt loss of MEPs and diminished SSEPs in the bilateral upper and lower extremities (Figure 2). Hardware had not yet been placed, and the cervical spinal cord was fully decompressed. MAP was $115 \mathrm{mmHg}$, and no change had been made to the anesthetic regimen. The patient's MAP had been maintained at 85 to $133 \mathrm{mmHg}$ throughout the procedure. His temperature was $35.6^{\circ} \mathrm{C}$, and estimated blood loss at the time of signal loss was $100 \mathrm{~mL}$. The cord was normal in appearance but was noted to expand dramatically. No cerebrospinal fluid (CSF) leak or hemorrhage was noted. Noting the sudden cord expansion and edema, the surgeon suspected a diagnosis of white cord syndrome. The patient was given intravenous (IV) dexamethasone $8 \mathrm{mg}$ in the operating room (he had received $4 \mathrm{mg}$ of dexamethasone preoperatively for postoperative nausea prophylaxis).

The C2-T1 fusion was completed, but MEPs and SSEPs never improved during the remainder of the procedure. The patient was extubated and transferred to the neurosurgical intensive care unit. His initial physical examination 

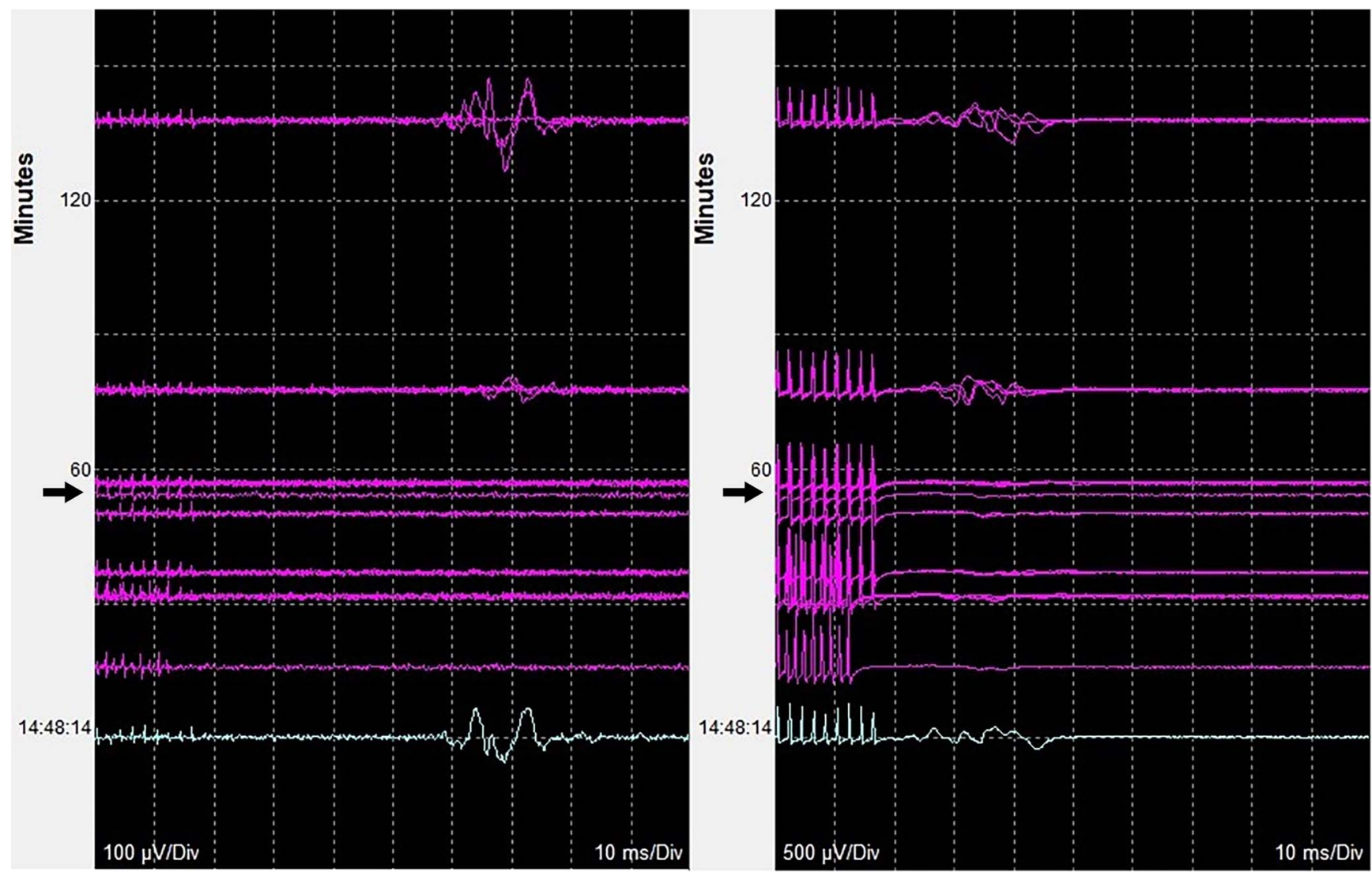

Figure 2. Intraoperative neurophysiologic monitoring for left triceps (left) and left extensor hallucis brevis-abductor hallucis muscles (right) demonstrates baseline motor evoked potentials (top and repeated for reference purpose at bottom) and subsequent loss of signals (arrows) approximately 90 minutes after incision.

demonstrated lack of sensation below the T3 level and 0/5 motor strength of all muscle groups except $4 / 5$ strength of bilateral deltoids. Postoperative hemoglobin was $13.9 \mathrm{~g} / \mathrm{dL}$.

During his hospitalization, the patient improved with IV dexamethasone therapy. He received $8 \mathrm{mg}$ every 6 hours for the first 48 hours, followed by 4 mg every 6 hours for the next 72 hours. Oral dexamethasone was then tapered for 2 weeks. The patient's neurologic examination on the date of discharge revealed a T10 sensory level and 2/5 motor strength of bilateral lower extremities with the exception of $3 / 5$ motor strength of bilateral knee extension and hip flexion. His upper extremities had returned to $5 / 5$ strength with the exception of 4/5 in grip strength bilaterally.

The patient was discharged to an inpatient rehabilitation center on postoperative day 10 where he completed 3 hours of physical therapy daily for 4 weeks. The patient was discharged from inpatient rehabilitation on postoperative day 30 with bilateral upper and lower extremity strength of $5 / 5$ with the exception of $4 / 5$ bilateral dorsiflexion (Nurick grade 4, mJOA score of 13). He then completed 8 weeks of home and outpatient physical therapy. A postoperative MRI was not performed.

\section{DISCUSSION}

Chin et al first described white cord syndrome in 2013 , noting the white appearance of the spinal cord edema observed on postoperative T2-weighted MRI. ${ }^{4}$ The patho- physiology of white cord syndrome is hypothesized to be attributable to oxygen-derived free radical damage after rapid cord expansion and reperfusion..$^{4,6}$ In a chronically compressed ischemic spinal cord, the blood-spinal cord barrier is disrupted, creating an area of spinal cord that is vulnerable to reperfusion injury upon decompression. Chronic compression creates an endothelial milieu prone to damage by oxygen-derived free radicals, causing loss of capillary contact with astrocyte foot processes. ${ }^{4,9}$ The disrupted blood-spinal cord interface allows for tumor necrosis factor- $\alpha$ migration and apoptotic pathway activation. ${ }^{4,9}$ This pathophysiologic mechanism has been simulated in mouse models. ${ }^{10}$ In mice with severely compressed spinal cords, oxidative stress indicators increased after decompression. In contrast, mice with mildly compressed cords did not exhibit these indicators after reperfusion.

Taher and colleagues have proposed neuropraxia attributable to recoil and change in the cross-sectional dimension of the cord as an etiology. ${ }^{11}$ The pathogenesis of white cord syndrome warrants investigation, with mechanical, vascular, and biochemical factors all playing some role.

Regardless of the true pathophysiologic mechanism, suspected cases of white cord syndrome warrant collaborative efforts between surgeons and anesthesiologists to avoid poor neurologic outcomes. Anesthesiologists manage blood pressure intraoperatively, and the hemodynamics 
surrounding the development of white cord syndrome warrants rethinking of blood pressure goals. Spinal cord perfusion mimics the perfusion of the brain because spinal cord perfusion depends upon the difference between MAP and CSF pressure. The autoregulatory zone of stable cerebral perfusion is classically described as a range from 70 to $150 \mathrm{mmHg}$. However, this range is likely higher in patients with chronic hypertension or spinal cord ischemia, meaning that these patients require a higher MAP intraoperatively to stay within the autoregulatory zone. Miller's Anesthesia recommends maintaining MAP within $10 \%$ of the patient's baseline MAP for patients with acute spinal cord injury, although stricter control may be required in patients with myelopathy or trauma to the spine. ${ }^{12}$ Various sources cite MAP goals of 80 to $85 \mathrm{mmHg}$ for spine surgery, ${ }^{12-15}$ yet this value seems to have been selected based on traumatic spinal cord injury studies. ${ }^{16}$ This MAP goal was originally chosen arbitrarily, and its benefit has been debated. ${ }^{17} \mathrm{~A}$ 2017 systematic review of 9 separate case series of patients with spinal cord injuries concluded that a MAP goal of 85 to $90 \mathrm{mmHg}$ for 5 to 7 days after injury should be considered, given the limitation that most studies are retrospective and have a low sample size. ${ }^{13}$ Despite the lack of high-quality evidence, the American Association of Neurological Surgeons and Congress of Neurological Surgeons joint guidelines recommend maintaining MAP of at least $85 \mathrm{mmHg}$ for patients with spinal cord injuries. ${ }^{15}$ Even less evidence is available to guide intraoperative blood pressure management for spinal surgery, so the spinal cord injury recommendations have been applied to the operating room.

IONM has become the standard of care for spinal surgery. Loss of intraoperative signals is indicative of direct cord injury, compression, or ischemia. In a 2018 series of 452 pediatric scoliosis repairs, Yang et al showed that raising MAP alone was curative in restoring $20 \%$ of lost IONM signals. ${ }^{18}$ Anecdotal evidence from practicing neurophysiologists concurs with this finding that blood pressure alteration often improves intraoperative signals. Our patient's MAP was lowest after induction of anesthesia, reaching a nadir of $85 \mathrm{mmHg}$, yet IONM signals remained strong for the first 90 minutes of the procedure. At the time of decompression, MAP was $115 \mathrm{mmHg}$, raising the question of what the MAP value for appropriate spinal cord perfusion should have been. Perhaps this MAP was actually too high. Given that the suspected pathophysiology of white cord syndrome is a reperfusion phenomenon, perhaps a high MAP delivers too much mechanical flow and too high an oxygenderived free radical load to the cord. Studies have shown that hypertension following mechanical thrombectomy for large vessel occlusions increases complications and worsens outcomes, ${ }^{19,20}$ which has led many centers to maintain systolic blood pressure $<140 \mathrm{mmHg}$ after successful recannulization. ${ }^{21}$ In the same way that blood pressure targets are decreased after thrombectomy of a large vessel occlusion due to open reperfusion, ${ }^{19}$ reduction of the MAP target after decompression of a chronically compressed cord may reduce cord edema and reperfusion injury. Future studies for spinal surgeries should investigate not only minimum MAP goals but should also include maximum MAP goals to better guide providers in the neurosurgical care team.

CSF pressure may also be a factor to consider in the management of white cord syndrome. At the site of a newly decompressed spinal cord, CSF pressure is increased, and this finding is corroborated by surgeons in real time with visual bulging of the thecal sac intraoperatively. ${ }^{11}$

Because spinal cord perfusion is dependent on CSF pressure, preoperative placement of a CSF drain may aid in anesthetic management of a patient with a severely compressed spinal cord. Elevated CSF pressures inhibit perfusion to the edematous cord, so gradually reducing CSF pressure prior to complete decompression, if we had considered it, may have mitigated cord edema in our patient.

Although clinical experience and animal models imply that the severity of compression corresponds with the degree of neurologic deficit, ${ }^{10}$ studies attempting to correlate the degree of T2-weighted signal change with neurologic outcome have been inconclusive. ${ }^{22}$

\section{CONCLUSION}

Case numbers are insufficient to determine particular risk factors for white cord syndrome. High preoperative T2 signal intensity has been a consistent finding in all published case reports, including ours. Studies are needed to clarify risk factors, characterize the pathophysiology, and determine the appropriate perioperative management of this rare syndrome.

\section{ACKNOWLEDGMENTS}

The authors have no financial or proprietary interest in the subject matter of this article.

\section{REFERENCES}

1. Cramer DE, Maher PC, Pettigrew DB, Kuntz C 4th. Major neurologic deficit immediately after adult spinal surgery: incidence and etiology over 10 years at a single training institution. J Spinal Disord Tech. 2009 Dec;22(8):565-570. doi: 10.1097/BSD.0b013e318193452a.

2. Thirumala $P$, Zhou J, Natarajan $P$, et al. Perioperative neurologic complications during spinal fusion surgery: incidence and trends. Spine J. 2017 Nov;17(11):1611-1624. doi: 10.1016/j.spinee.2017.05.020.

3. Seichi A, Takeshita K, Kawaguchi H, Nakajima S, Akune T, Nakamura K. Postoperative expansion of intramedullary high-intensity areas on T2-weighted magnetic resonance imaging after cervical laminoplasty. Spine (Phila Pa 1976). 2004 Jul 1;29(13):1478-1482.

doi: 10.1097/01.brs.0000128757.32816.19.

4. Chin KR, Seale J, Cumming V. "White cord syndrome" of acute tetraplegia after anterior cervical decompression and fusion for chronic spinal cord compression: a case report. Case Rep Orthop. 2013;2013:697918. doi: 10.1155/2013/697918.

5. Giammalva GR, Maugeri R, Graziano F, et al. White cord syndrome after non-contiguous double-level anterior cervical decompression and fusion (ACDF): a "no reflow phenomenon"? Interdiscip Neurosurg. 2017 Mar;7:47-49.

doi: 10.1016/j.inat.2016.12.001.

6. Antwi P, Grant R, Kuzmik G, Abbed K. "White Cord Syndrome" of acute hemiparesis after posterior cervical decompression and fusion for chronic cervical stenosis. World Neurosurg. 2018 May;113:33-36. doi: 10.1016/j.wneu.2018.02.026.

7. Vinodh VP, Rajapathy SK, Sellamuthu P, Kandasamy R. White cord syndrome: a devastating complication of spinal decompression surgery. Surg Neurol Int. 2018 Jul 13;9:136. doi: 10.4103/sni.sni_96_18.

8. Grayev A. Spinal cord signal abnormality with enhancement. J Am Osteopath Coll Radiol. 2015 Oct 1;4(4):20-22. 
9. Jaeger CB, Blight AR. Spinal cord compression injury in guinea pigs: structural changes of endothelium and its perivascular cell associations after blood-brain barrier breakdown and repair. Exp Neurol. 1997 Apr;144(2):381-399. doi: 10.1006/exnr.1996.6405.

10. Wu L, Yang T, Yang C, et al. Delayed neurological deterioration after surgery for intraspinal meningiomas: ischemia-reperfusion injury in a rat model. Oncol Lett. 2015 Oct;10(4):2087-2094. doi: 10.3892/ol.2015.3626.

11. Taher F, LebI DR, Cammisa FP, Pinter DW, Sun DY, Girardi FP. Transient neurological deficit following midthoracic decompression for severe stenosis: a series of three cases. Eur Spine J. 2013 Sep;22(9):2057-2061. doi: 10.1007/s00586-013-2829-y.

12. Drummond JC, Patel PM, Lemkuil BP. Anesthesia for neurologic surgery. In: Miller RD, ed. Miller's Anesthesia. 8th ed. Philadelphia, PA: Elsevier/Saunders; 2014:2158-2199.

13. Saadeh YS, Smith BW, Joseph JR, et al. The impact of blood pressure management after spinal cord injury: a systematic review of the literature. Neurosurg Focus. 2017 Nov;43(5):E20. doi: 10.3171/2017.8.FOCUS17428.

14. Hawryluk G, Whetstone W, Saigal R, et al. Mean arterial blood pressure correlates with neurological recovery after human spinal cord injury: analysis of high frequency physiologic data. J Neurotrauma. 2015 Dec 15;32(24):1958-1967. doi: 10.1089/neu.2014.3778.

15. Ryken TC, Hurlbert RJ, Hadley MN, et al. The acute cardiopulmonary management of patients with cervical spinal cord injuries. Neurosurgery. 2013 Mar;72 Suppl 2:84-92. doi: 10.1227/NEU.0b013e318276ee16.

16. Vale FL, Burns J, Jackson AB, Hadley MN. Combined medical and surgical treatment after acute spinal cord injury: results of a prospective pilot study to assess the merits of aggressive medical resuscitation and blood pressure management. $J$ Neurosurg. 1997 Aug;87(2):239-246. doi: 10.3171/jns.1997.87.2.0239.

17. Martin ND, Kepler C, Zubair M, Sayadipour A, Cohen M, Weinstein $M$. Increased mean arterial pressure goals after spinal cord injury and functional outcome. J Emerg Trauma Shock. 2015 Apr-Jun;8(2):94-98. doi: 10.4103/0974-2700.155507.

18. Yang J, Skaggs DL, Chan P, et al. Raising mean arterial pressure alone restores $20 \%$ of intraoperative neuromonitoring losses. Spine (Phila Pa 1976). 2018 Jul 1;43(13):890-894. doi: 10.1097/BRS.0000000000002461.

19. Mistry EA, Mistry AM, Nakawah MO, et al. Systolic blood pressure within 24 hours after thrombectomy for acute ischemic stroke correlates with outcome. J Am Heart Assoc. 2017 May 18;6(5):e006167. doi: 10.1161/JAHA.117.006167.

20. Anadani M, Orabi MY, Alawieh A, et al. Blood pressure and outcome after mechanical thrombectomy with successful revascularization. Stroke. 2019 Sep;50(9):2448-2454. doi: 10.1161/STROKEAHA.118.024687.

21. Patel VN, Gupta R, Horn CM, Thomas TT, Nogueira RG. The neuro-critical care management of the endovascular stroke patient. Curr Treat Options Neurol. 2013 Apr;15(2):113-124. doi: 10.1007/s11940-012-0216-3.

22. Machino M, Ando K, Kobayashi K, et al. Alterations in intramedullary $\mathrm{T} 2$-weighted increased signal intensity following laminoplasty in cervical spondylotic myelopathy patients: comparison between pre- and postoperative magnetic resonance images. Spine (Phila Pa 1976). 2018 Nov 15;43(22):1595-1601. doi: 10.1097/BRS.0000000000002674.

This article meets the Accreditation Council for Graduate Medical Education and the American Board of Medical Specialties Maintenance of Certification competencies for Patient Care and Medical Knowledge.

(C2020 by the author(s); licensee Ochsner Journal, Ochsner Clinic Foundation, New Orleans, LA. This article is an open (c) (i) access article distributed under the terms and conditions of the Creative Commons Attribution (CC BY) license (creativecommons.org/licenses/by/4.0/legalcode) that permits unrestricted use, distribution, and reproduction in any medium, provided the original author(s) and source are credited. 